\title{
Molecular epidemiology of human metapneumovirus (hMPV) in Cambodia
}

\author{
Alicia Arnott ${ }^{*}$, Mardy Sek, Sirenda Vong, Philippe Buchy \\ From Institut Pasteur International Network Annual Scientific Meeting \\ Hong Kong. 22-23 November 2010
}

\section{Background}

First identified in 2001, human metapneumovirus (hMPV) is a novel pathogen and causative agent of acute respiratory tract infection. Re-infection with hMPV is common, and currently there is no available vaccine against this virus. Two genetic subgroups (A and B) have been identified, both of which can be divided further into at least two distinct sub-lineages. Here we report the results of the genetic variability of hMPV strains circulating within Cambodia.

\section{Methods}

A total of 3858 samples were collected, between 20072009, from hospitalized patients presenting with acute lower respiratory illness in the regional hospitals of Takeo and Kampong Cham, under the guidelines of the SISEA (Surveillance and Investigation of Epidemic Situations in Southeast Asia) project. Nasopharyngeal samples were tested for 18 respiratory viruses using multiplex PCR/RT-PCR at the Institut Pasteur in Cambodia. To investigate the genetic heterogeneity of hMPV strains in Cambodia, regions within the highly variable G gene, and highly conserved $F$ gene of 65 strains were amplified. Neighbour-Joining trees were constructed using Mega 4.0 software.

\section{Results}

Most of hMPV cases occurred in 2008 (89\%) with a peak in August (32\%). Only a very low number of hMPV positive samples were detected in November and December 2007 and in 2009. Partial F gene sequences were obtained from 48 samples, collected from patients between 3 months and 58 years of age. Phylogenetic analysis revealed the co-circulation of B2 (91\%) and A2 (9\%) genotypes. Genotypes A1 and B1 were not detected. Twenty eight partial G gene sequences were generated. Phylogenetic analysis results were consistent between the $\mathrm{F}$ and $\mathrm{G}$ genes. We observed more than $10 \%$ diversity at the nucleotide level between $\mathrm{G}$ gene sequences clustering within the B2 genotype.

\section{Conclusion}

This is the first study to investigate the molecular epidemiology of hMPV in Cambodia, and the first study to report a predominance of circulating genotype B2 strains in Southeast Asia. Our findings contribute to those of recent studies, demonstrating the high variability of the global distribution of hMPV genotypes. This emphasizes the need for ongoing genetic characterization of circulating strains to aid generation of an effective vaccine.

\section{Acknowledgements}

Supported by the French Development Agency through the Surveillance and Investigation of Epidemic Situations in Southeast Asia (SISEA) project.

Published: 10 January 2011

doi:10.1186/1753-6561-5-S1-P71

Cite this article as: Arnott et al:: Molecular epidemiology of human metapneumovirus (hMPV) in Cambodia. BMC Proceedings 2011 5(Suppl 1): P71.

Institut Pasteur in Cambodia, Phnom Penh, Cambodia

(c) 2011 Arnott et al; licensee BioMed Central Ltd. This is an open access article distributed under the terms of the Creative Commons B.oWed Central Attribution License (http://creativecommons.org/licenses/by/2.0), which permits unrestricted use, distribution, and reproduction in any medium, provided the original work is properly cited. 